\title{
Do Blockchain Stocks Exhibit More Herding Behaviour than Traditional Stocks?
}

\author{
Prakhar Goel ${ }^{1}$ and Abhishek Dev ${ }^{\#}$ \\ ${ }^{1}$ Hill Spring International School, Mumbai, India \\ \#Advisor
}

\section{ABSTRACT}

While the volatile behaviour of cryptocurrency is extensively studied, the stock market's blockchain sector, which has not been given much attention in the academic world, operates very differently from traditional stock industries. The paper hypothesizes that blockchain stocks exhibit more herding behaviour than traditional stocks and uses quantitative data analysis techniques to study it. The automotive industry is taken as a representative of traditional stocks. CrossSectional Absolute Deviation, the academic standard for herding behaviour, is used as the primary comparative measure between blockchain and automotive stocks. It reveals that blockchain industry has significant herding, while rational pricing mechanisms prevail in the automotive industry. Supporting this conclusion, a correlation matrix of stock prices of small market capitalisation firms in each industry is constructed, analysing how closely stock price movements in an industry are related. The correlation coefficient for blockchain stocks is $20 \%$ higher than the coefficient for automotive stocks. This indicates that blockchain stocks likely exhibit higher levels of herding. The impact of social media on stock price movements in the two industries is analysed by conducting a correlation study between Google Trends data for industry-related keywords and individual stock returns. The blockchain industry saw a significantly higher correlation, likely suggesting that social media has a stronger influence on blockchain stock price movements. Finally, the paper provides possible explanations for why herding behaviour is more prominent in the blockchain stocks compared to traditional stocks. These include absence of traditional stock valuation metrics, lack of financial knowledge and role of social media.

\section{Introduction}

A disruptive force in the financial sector today, the blockchain industry forms the bedrock of several cryptocurrencies, including Bitcoin, as it decentralises authority by spreading control and processes across a network of computers. The blockchain market has been a fortunate beneficiary of the recent rise in interest in cryptocurrency. To put cryptocurrency's rise into perspective, the first quarter of 2021 saw a 400\% increase in value of Bitcoin (Bambrough, 2021). In fact, it is the third most-used payment network in the world after Visa Card and MasterCard. Every cryptocurrency mined, wallet created and payment transacted is stored on blockchain ledgers. Therefore, the rise of cryptocurrencies has led to a tremendous growth in the blockchain market. In fact, in Deloitte's Global Blockchain Survey, 55\% of company executives stated that blockchain is critical for their organisation and is a top-five strategic priority in the 2 upcoming years (Deloitte Insights, 2021). The compound annual growth rate (CAGR) for the blockchain industry from 2021-2025 is expected to be 56.9\%, making it one of the fastest growing sectors. This is significantly higher than the more traditional markets like automotive (12.42\%), banking (5.27\%) and power (7.02\%) as well as emerging technological industries like cyber security (13.3\%), Internet of Things (27.6\%), 3D printing (22\%), cloud services (19.1\%) and robotics (10.9\%) (BBC Research) (NYU Stern, 2021).

Given its market opportunity and potential, the blockchain sector is likely to witness billions of dollars of investments in the near future. It would be useful to understand the dynamics relating to stock price movements of 
companies in the sector especially because the blockchain sector functions very differently from traditional industries. Firm-specific news and key developments, which usually impact traditional stocks significantly, may not play a very important role in blockchain stocks, given the general lack of knowledge regarding blockchain technology as also the ability to understand the financials of such companies, given their stage of evolution. On the other hand, herding behaviour could be a major factor in blockchain stocks, due to various causes, ranging from the absence of traditional stock valuation metrics, lack of financial knowledge on the subject, as well as role of social media.

In the academic world so far, there has been extensive research conducted regarding herding behaviour, in general, and in traditional industries, in particular. For example, 'International Herding: Does it differ across sectors?' uses stock market data from various geographies to study herding behaviour in various traditional stock industries like oil, gas and basic materials (Gebka and Wohar, 2013). Even in the cryptocurrency world, which is closely linked to blockchain technology, herding behaviour has been studied using a variety of methods, including CSSD and CSAD (Vidal-Tomás et al., 2018), Forbes and Robogon (Gama Silva, 2019) and GARCH Model (Ballis and Drakos, 2020). While herding in the cryptocurrency world has been well explored by researchers, a large knowledge gap exists when it comes to the dynamics of the blockchain industry, which this paper tries to address. This paper contributes research to the blockchain stock industry, which has not been studied much in the academic world yet, and the paper can serve as a base for future research by other academics. In addition to using previously established measures of herding behaviour, this paper introduces novel techniques and data analysis studies to examine the herding behaviour in blockchain stocks.

The paper compares blockchain stocks' data to one traditional industry, automotive. The results of the various studies conducted prove that herding behaviour is significantly more prominent in blockchain stocks, as compared to automotive. The Cross-Sectional Absolute Deviation (CSAD), which is the primary measure for comparison, revealed that the blockchain stock industry has a significant extent of herding behaviour, while automotive stocks clearly follow rational stock pricing methods. This is supported by a correlation matrix study conducted on daily prices of a sample of blockchain stocks and a sample of automotive stocks. The study reveals that stock prices in the blockchain industry, as a whole, generally move in tandem, as compared to those in the automotive industry. Moreover, a study is conducted comparing the number of Google searches for certain industry-specific keywords, a representation of social media interest in the industry, to stock returns. While the impact of social media on automotive stocks is negligible, the relationship and correlation are relatively much stronger for the blockchain industry.

The paper first summarizes existing research done in fields relevant to the research topic. Then, the methods used in the study are explained, after which the results are presented. The methods and results are each divided into sub-sections of 'CSSD', 'CSAD', 'Stock Price Correlation Matrix' and 'Correlation between Social Media Hype and Stock Prices', which are the various data analysis studies conducted. Finally, the paper discusses possible reasons for the difference in herding behaviour between the two industries.

\section{Literature}

The idea of quantifying herding behaviour was first introduced by Christie and Huang in 1995 in their paper, 'Following the Pied Piper: Do Individual Returns Herd around the Market?'. Cross-Sectional Standard Deviation (CSSD) of stock returns during periods of market stress was used as a measure to determine the extent to which herding behaviour was present. Herding behaviour was indicated by low values of CSSD, as investors are likely suppressing their own financial knowledge and intuition about specific companies to blindly follow the market consensus. By analysing daily stock data from the New York Stock Exchange, the study found that even during periods of high market stress, herding is not an important influence on the equity returns, and instead, the evidence supported rational asset pricing models (Christie \& Huang, 1995).

In 2000, Chang et al.'s 'An Examination of Herd Behavior in Equity Markets: An International Perspective' improved on Christie and Huang's CSSD method and introduced an approach that provided a more accurate representation of herding behaviour in the stock market, CSAD. Additionally, this study, unlike the previous one, was 
conducted across international markets in 5 different countries. In Hong Kong, Japan and US, the study found insignificant signs of herding behaviour, which was consistent with Christie and Huang's findings. However, in emerging markets like South Korea and Taiwan, there were prominent signs of herding behaviour, and macroeconomic information was found to play an extremely important role in the decision-making process of the market agents (Chang et al., 1999).

Other papers have found more specific trends showing where herding behaviour tends to be more significant. While examining the trading activity of mutual funds between 1975 to 1994, one of the key findings of Wermers' 'Mutual Fund Herding and the Impact on Stock Prices' was that there is a significantly higher level of herding while trading small market capitalisation stocks, as compared to the larger ones (Wermers, 1998). While there has not been research conducted on blockchain stocks in particular, there has been some study of Financial and Technology industries. Zheng et al.'s 'Herding withing industries: Evidence from Asian stock markets' uses data from different Asian countries to prove that herding is more significant in Technology and Financial industries, as compared to the Utility industry (Zhang et al., 2017). Cakan and Balagyozyan's 'Sectoral Herding: Evidence from an Emerging Market' further builds on this conclusion by studying data from the Turkish stock market, finding that herding behaviour is prominent in the Technology and Financial industries especially in highly volatile markets and during periods of rising markets (Cakan and Balagyozyan, 2013).

Since the cryptocurrency world and blockchain technology are closely related, it would be useful to study past papers on herding in the cryptocurrency markets. Vidal-Tomás et al.'s 'Herding in the cryptocurrency market: CSSD and CSAD approaches' concludes that herding behaviour is most prominent in the cryptocurrency market in periods of down markets, indicating the major risk and volatility of cryptocurrencies. Moreover, traders base their buy/sell decisions for smaller currencies based on the performance of the few largest cryptocurrencies rather than using their financial knowledge regarding the specific currencies, which is a clear sign of herding (Vidal-Tomás et al., 2018). Gama Silva supported this claim by using the Forbes and Rogobon's (2002) test in his paper, 'Herding behavior and contagion in the cryptocurrency market', which proved that the performance of Bitcoin impacted all other cryptocurrencies considered in that study, i.e. the Bitcoin contagion extended across almost the entire cryptocurrency market (Gama Silva, 2019). In 'Testing for herding in the cryptocurrency market', using a GARCH model, Ballis and Drakos found that herding exists in the "top" 6 cryptocurrencies, and that such behaviour is evident in both up and down markets (Ballis and Drakos, 2020). In 'Herding and anchoring in cryptocurrency markets: Investor reaction to fear and uncertainty', Gurdigiev and O'Loughlin use a different method to analyse herding. Sentiment analysis of the investors accurately predicted the price direction of cryptocurrencies, thus portraying significant herding in the market (Gurdgiev \& O’Loughlin, 2020).

This paper focuses on herding behaviour in blockchain stocks, rather than cryptocurrency, and compares it with traditional stock industries. The automotive stock industry is taken as a representative of the latter.

\section{Methods}

In order to compare herding behaviour between the blockchain and automotive industries, CSSD and CSAD are the primary comparative measures used. In addition to that, various other data analyses have been conducted to support and fortify the conclusions.

\section{CSSD and CSAD}

The CSSD and CSAD studies followed the steps laid out in Christie and Huang (1995) and Chang et al. (2000) respectively, in order to calculate the extent of herding in the blockchain and automotive industries. 21 individual stock firms were selected to be studied from the blockchain and automotive industry each. The following are the formulae used while calculating each of them. 


$$
\begin{gathered}
C S S D=a+b_{1} U P+b_{2} D O W N+\varepsilon \\
C S A D=a+b_{1} r_{m}^{2}+b_{2}\left|r_{m}\right|+b_{3} r_{m}+\varepsilon
\end{gathered}
$$

For the purpose of this paper, a 'blockchain' firm is one that is involved in designing, producing, selling or investing in blockchain technology. The blockchain stocks used are all listed in either US or Canadian stock exchanges. An 'automotive' firm is one that is involved in producing and selling automotive vehicles or automotive parts. The automotive stocks used are listed in US stock exchanges. Each sample is a combination of small and large market capitalisation stocks. The market capitalisations for the firms in the industry samples were obtained from Yahoo Finance. Daily data on stock prices between $1^{\text {st }}$ January, 2019 to $26^{\text {th }}$ May, 2021 for each of these firms was obtained from Yahoo Finance. The start date of $1^{\text {st }}$ January, 2019 has been taken to ensure that sufficient sample of blockchain listed stocks are available for analysis. Prior to that period, there were fewer listed firms in the blockchain sector. To measure the deviation of stock price returns in a particular industry from the average returns of the industry, the largest exchange-traded funds (ETFs) in the blockchain and automotive industries are used as the base for comparison. Amplify Transformational Data Sharing ETF is used for the blockchain sample and First Trust NASDAQ Global Auto Index Fund is used for the automotive sample. Daily data on its prices for the abovementioned time period was also obtained from Yahoo Finance.

The results of the CSSD and CSAD studies are to be analysed in the following way: (1) A negative coefficient value indicates herding behaviour, while a positive value indicates rational behaviour. (2) The size of the coefficient, ignoring the sign, is directly correlated to the significance of herding/rational behaviour. (3) The p-value indicates the probability that the values obtained for the coefficient are due to random chance. In CSSD, both coefficients, $b_{1}$ and $\mathrm{b}_{2}$, must be looked at while measuring herding behaviour. In CSAD, it is important to focus on the coefficient of $r_{m}^{2}$, $\mathrm{b}_{1}$, while measuring herding behaviour.

\section{Stock Price Correlation Matrix}

A correlation matrix is constructed to see how closely price movements of stocks in an industry are related. Since it is known that there tends to be more herding in smaller market capitalisation stocks, the 11 smallest market capitalisation stocks are taken from the 21 stocks in the original samples for the blockchain and automotive industries.

To construct the matrix for the blockchain industry, the Pearson product-moment correlation coefficient (PPMCC), as displayed below, is applied to daily stock data for each of the 11 firms selected with each of the other 10 firms. The same process is repeated for firms in the automotive industry.

$$
r_{x y}=\frac{\sum\left(x_{i}-\bar{x}\right)\left(y_{i}-\bar{y}\right)}{\sqrt{\sum\left(x_{i}-\bar{x}\right)^{2} \sum\left(y_{i}-\bar{y}\right)^{2}}}
$$

To find the average correlation between any 2 firms in the blockchain sample, the correlation efficient for each permutation of pairs is added up and then divided by the total number of pair permutations possible. The value obtained, for the purpose of this paper, is called the 'industry stock price average correlation coefficient'. The same process is repeated for firms in the automotive industry. It is more likely that industries with higher prominence of herding behaviour see their stocks moving in similar directions. Therefore, it is likely that the higher the average correlation efficient, the higher the prominence of herding behaviour in that industry.

\section{Correlation between Social Media Hype and Stock Prices}

One of the major factors causing herding behaviour is the role of social media. Using PPMCC, a correlation study is conducted to investigate the impact of social media-induced herding behaviour on stock price movements. The first 
variable used is the number of Google searches for keywords related to the concerned industry, obtained from Google Trends. This would be an appropriate representation of social media interest, given that Google has $93 \%$ of the global search engine market share. The keywords used for the blockchain industry are 'Blockchain', 'Bitcoin', 'Blockchain Stocks' and 'Blockchain Investments'. The keywords used for the automotive industry are 'Motors', 'Automotive', 'Car' and 'Car Stocks'. Monthly Google Trends data for each keyword was downloaded for all months from January 2019 to May 2021.

For the second variable, individual monthly stock returns for each firm in the industry sample are calculated using the formula below. This data captures the monthly percentage change in the stock price. Since there is no way of ascertaining whether Google searches are fluctuating due to positive or negative hype, the modulus value of the monthly stock returns is found, to only focus on the magnitude of change in stock price, rather than the direction.

$$
\text { Monthly stock return }=\frac{\text { Price at end of month }- \text { Price at start of month }}{\text { Price at start of month }} * 100
$$

Firstly, the number of searches for all 4 keywords pertaining to the relevant industry are aggregated. The correlation between this aggregate and modulus monthly stock returns for each of the 21 firms in the industry sample is found. This process obtains 21 correlation coefficients. The average of these 21 coefficients is found, which summarises the correlation between social media interest, represented by the Google searches for industry-related keywords, and stock price movements, represented by the monthly stock returns, for firms in the specific industry. This value, for the purpose of this paper, is called the 'industry media average correlation coefficient'.

If the correlation coefficient is positive and significant, it likely suggests that media hype and attention drive herding behaviour that influences stock prices. By comparing the final values obtained for both industries, one can determine which industry is more strongly impacted by social media-induced herding behaviour.

\section{Results}

\section{CSSD}

The CSSD regression for the blockchain and automotive industries returned positive coefficient values, albeit very small and insignificant, indicating rational behaviour by investors. However, the p-value for the automotive industry is much higher than the acceptable threshold of $5 \%$, thus indicating that these results could likely be simply due to random chance.

Table 1: Summary of CSSD results for blockchain industry

\begin{tabular}{|lccc|}
\hline \multicolumn{4}{c|}{ Christie and Huang (1995) CSSD regression } \\
\hline & $\mathbf{b}_{\mathbf{1}}$ & $\mathbf{b}_{\mathbf{2}}$ & $\boldsymbol{\varepsilon}$ \\
Coefficient & 0.051 & 0.044 & 0.084 \\
Standard error & 0.011 & 0.011 & 0.002 \\
& 0.052 & 0.060 & \\
& 16.597 & 601 & \\
& 0.123 & 2.233 & \\
& & & \\
t-stat & 4.481 & 3.850 & 32.286 \\
p-value & $0.00 \%$ & $0.01 \%$ & $0.00 \%$ \\
\hline
\end{tabular}


Table 1. A CSSD regression is conducted on daily stock price data of 21 blockchain firms, obtained from Yahoo Finance. To measure the deviation of stock price returns from the average returns of the blockchain industry, data of the Amplify Transformational Data Sharing ETF is used.

Table 2: Summary of CSSD results for automotive industry

\begin{tabular}{|c|c|c|c|}
\hline & \multicolumn{3}{|c|}{ Christie and Huang (1995) CSSD regression } \\
\hline & $\mathbf{b}_{1}$ & $\mathbf{b}_{2}$ & $\varepsilon$ \\
\hline Coefficient & 0.004 & 0.028 & 0.046 \\
\hline \multirow[t]{4}{*}{ Standard error } & 0.008 & 0.008 & 0.001 \\
\hline & 0.020 & 0.043 & \\
\hline & 6.408 & 601 & \\
\hline & 0.023 & 1.124 & \\
\hline t-stat & 0.530 & 3.563 & 24.990 \\
\hline p-value & $59.62 \%$ & $0.04 \%$ & $0.00 \%$ \\
\hline
\end{tabular}

Table 2. A CSSD regression is conducted on daily stock price data of 21 automotive firms, obtained from Yahoo Finance. To measure the deviation of stock price returns from the average returns of the automotive industry, data of the First Trust NASDAQ Global Auto Index Fund is used.

\section{CSAD}

On the other hand, the CSAD regression for blockchain and automotive industries is far more insightful, returning low p-values. ${ }^{1}$ Furthermore, CSAD is commonly considered an improved version of CSSD, and hence, it yields more reliable findings. The return-squared coefficient, $b_{1}$, for the blockchain industry is negative and fairly significant, thus indicating prominent herding behaviour in the industry. On the other hand, the automotive industry has a positive and significant $b_{1}$ coefficient, suggesting that rational pricing mechanisms play the major role in this industry. Therefore, the clear difference in herding behaviour between the blockchain stock industry and traditional industries like automotive is evident through this study.

Table 3: Summary of CSAD results for blockchain industry

\begin{tabular}{|c|c|c|c|c|}
\hline \multicolumn{5}{|c|}{ Chang et al. (2000) CSAD Regression } \\
\hline \multirow{5}{*}{$\begin{array}{l}\text { Coefficient } \\
\text { Standard Error }\end{array}$} & $b_{1}$ & $\mathbf{b}_{2}$ & $\mathbf{b}_{3}$ & $\varepsilon$ \\
\hline & -2.663 & 0.815 & 0.088 & 0.043 \\
\hline & 1.351 & 0.120 & 0.038 & 0.001 \\
\hline & 0.211 & 0.022 & & \\
\hline & 53.505 & 600 & & \\
\hline
\end{tabular}

\footnotetext{
${ }^{1}$ Although the p-value in CSAD for the automotive industry is slightly greater than the acceptable threshold of 5\%, it is much lower than the corresponding p-value in the automotive CSSD study.
} 


\begin{tabular}{|lrrrr|} 
& 0.083 & 0.312 & & \\
t-stat & & & & \\
p-value & -1.971 & 6.758 & 2.275 & 29.374 \\
\hline
\end{tabular}

Table 3. A CSAD regression is conducted on daily stock price data of 21 blockchain firms, obtained from Yahoo Finance. To measure the deviation of stock price returns from the average returns of the blockchain industry, data of the Amplify Transformational Data Sharing ETF is used.

Table 4: Summary of CSAD results for automotive industry

\begin{tabular}{|c|c|c|c|c|}
\hline \multicolumn{5}{|c|}{ Chang et al. (2000) CSAD Regression } \\
\hline \multirow{3}{*}{$\begin{array}{l}\text { Coefficient } \\
\text { Standard error }\end{array}$} & $\mathbf{b}_{1}$ & $\mathbf{b}_{2}$ & $\mathbf{b}_{3}$ & $\varepsilon$ \\
\hline & 6.972 & 0.172 & 0.105 & 0.029 \\
\hline & 4.568 & 0.183 & 0.063 & 0.001 \\
\hline & 0.039 & 0.017 & & \\
\hline & 8.290 & 600 & & \\
\hline & 0.007 & 0.181 & & \\
\hline t-stat & 1.526 & 0.941 & 1.665 & 23.137 \\
\hline p-value & $12.75 \%$ & $34.69 \%$ & $9.63 \%$ & $0.00 \%$ \\
\hline
\end{tabular}

Table 4. A CSAD regression is conducted on daily stock price data of 21 automotive firms, obtained from Yahoo Finance. To measure the deviation of stock price returns from the average returns of the automotive industry, data of the First Trust NASDAQ Global Auto Index Fund is used.

\section{Stock Price Correlation Matrix}

The correlation matrix studies also returned results supporting the previously mentioned conclusions. The industry stock price average correlation coefficient for the blockchain industry is $53.52 \%$, significantly greater than the size of the industry stock price average correlation coefficient for the automotive industry, 33.74\%. This suggests that blockchain stocks move together in much similar directions, as compared to automotive stocks, which could signal herding behaviour. 

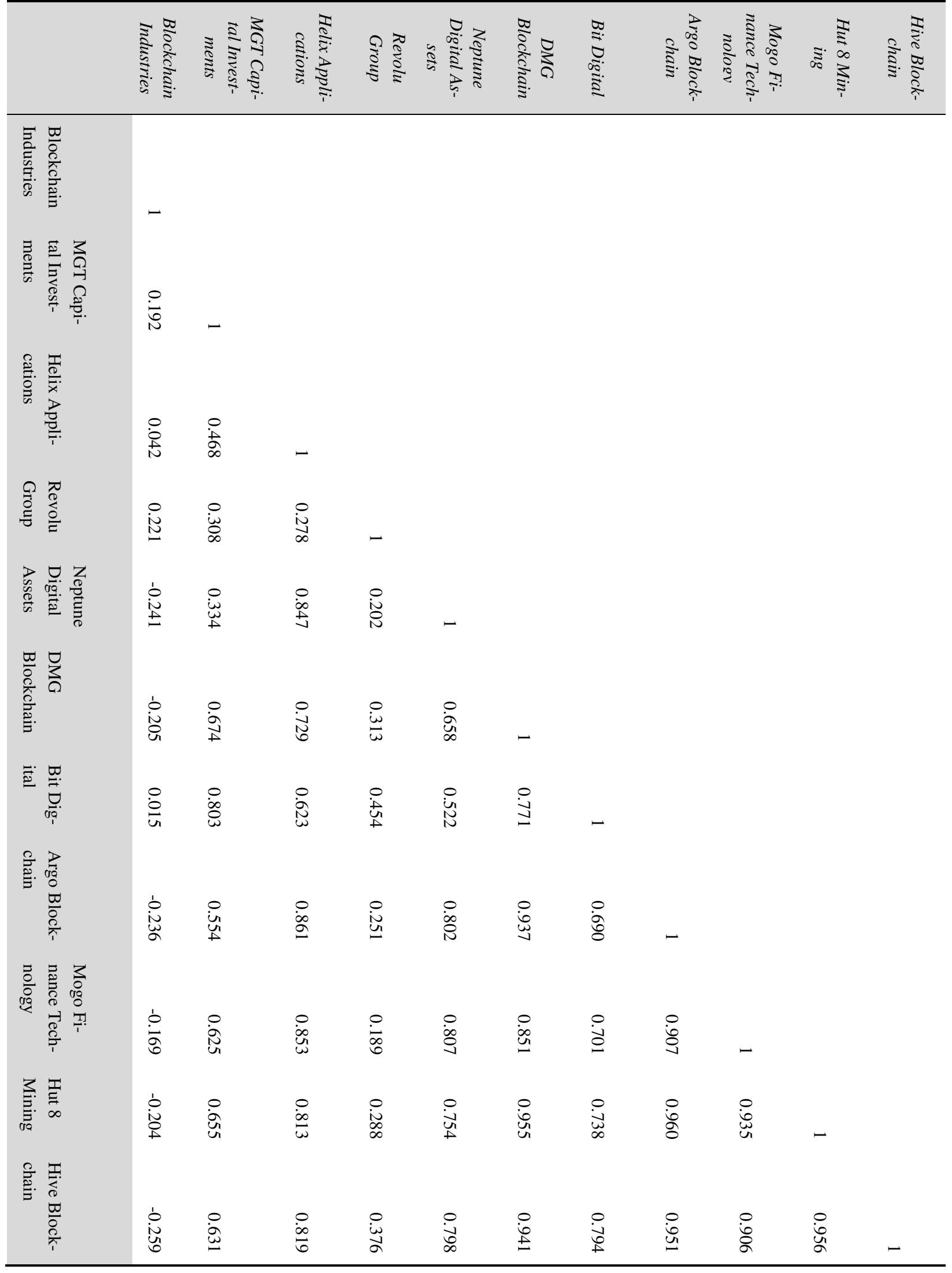


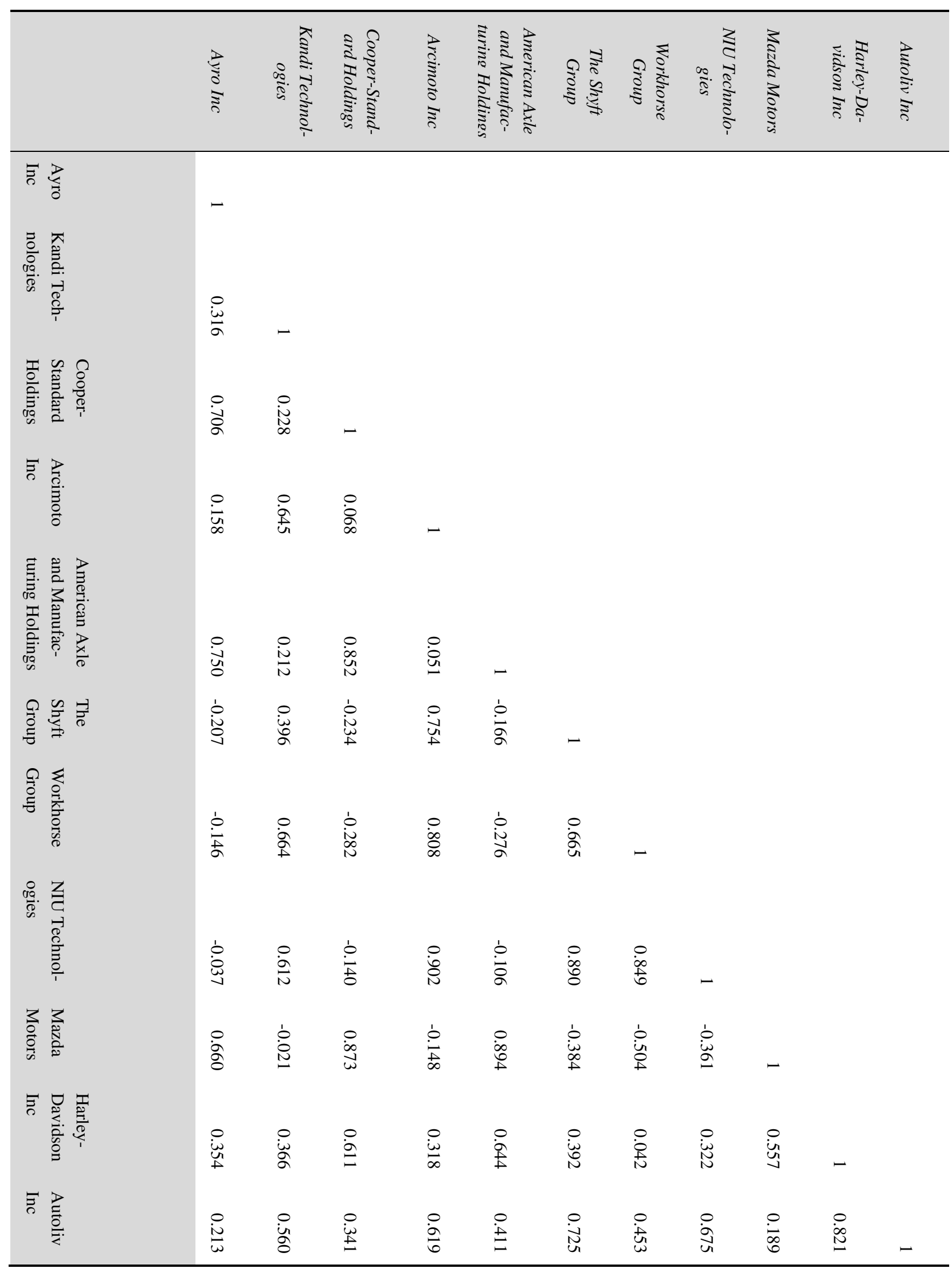


Table 5. A correlation matrix is constructed using prices of the 11 smallest market capitalization blockchain stocks in the sample. PPMCC is applied on the daily stock data for each of the 11 firms selected with each of the other 10 firms. Table 6 . A correlation matrix is constructed using prices of the 11 smallest market capitalization automotive stocks in the sample. PPMCC is applied on the daily stock data for each of the 11 firms selected with each of the other 10 firms.

\section{Correlation between Social Media Hype and Stock Prices}

The industry media average correlation coefficient for blockchain is $18.92 \%$, significantly higher than the automotive industry's $-9.25 \%$. The blockchain stocks had a positive coefficient, while the automotive stocks had a negative correlation. A positive correlation indicates that social media does influence stock price movements in the blockchain industry. It suggests that, on a relative basis, social media significantly drives price movements in the blockchain stock industry. The difference in correlation coefficient between the blockchain and automotive stocks is $28.2 \%$, which is fairly significant. Moreover, the p-value, $0.05 \%$ is extremely low, further increasing the significance of these results.

Table 7: Correlation coefficients between monthly Google searches for blockchain-related keyword and monthly firm stock returns

\begin{tabular}{|lr|} 
Correlation Coefficients Between & Key- \\
word Searches and Firm Stock & Prices \\
\hline Nvidia & -0.192 \\
Square & -0.229 \\
CME Group & -0.060 \\
DocuSign & -0.113 \\
MicroStrategy Incorporated & 0.409 \\
Overstock.com & -0.011 \\
Riot Blockchain & 0.299 \\
Marathon Digital Assets & -0.035 \\
Galaxy Digital Holdings & 0.427 \\
Currencyworks & 0.237 \\
Hive Blockchain & 0.136 \\
Hut 8 Mining & 0.465 \\
Mogo Finance Technology & 0.178 \\
Argo Blockchain & 0.663 \\
Bit Digital & -0.058 \\
DMG Blockchain & 0.577 \\
Neptune Digital Assets & 0.201 \\
Revolu Group & 0.057 \\
Helix Applications & 0.588 \\
MGT Capital Investments & 0.350 \\
Blockchain Industries & 0.082 \\
Mean & $\mathbf{0 . 1 8 9}$ \\
\hline
\end{tabular}

Table 8: Correlation coefficients between monthly Google searches for automotive-related keyword and monthly firm stock returns

\begin{tabular}{|c|c|}
\hline \multicolumn{2}{|c|}{$\begin{array}{c}\text { Correlation Coefficients Between Keyword } \\
\text { Searches and Firm Stock Prices }\end{array}$} \\
\hline Toyota Motors Company & 0.285 \\
\hline Daimler AG & -0.167 \\
\hline General Motors & -0.155 \\
\hline BMW & -0.200 \\
\hline NIO Inc & -0.041 \\
\hline Ford Motor Company & 0.087 \\
\hline Honda Motors Company & -0.277 \\
\hline Magna International & -0.233 \\
\hline Aisin Corporation & -0.108 \\
\hline Polaris Inc & -0.263 \\
\hline Autoliv Inc & -0.455 \\
\hline Harley-Davidson Inc & -0.123 \\
\hline Mazda Motors & -0.200 \\
\hline NIU Technologies & 0.389 \\
\hline Workhorse Group & 0.183 \\
\hline The Shyft Group & -0.208 \\
\hline American Axle and Manufa & \\
\hline Holdings & -0.378 \\
\hline Arcimoto Inc & 0.148 \\
\hline Cooper-Standard Holdings & -0.102 \\
\hline Kandi Technologies & 0.054 \\
\hline Ayro Inc & -0.172 \\
\hline Mean & -0.093 \\
\hline
\end{tabular}


Table 7. A PPMCC correlation study is conducted between the monthly aggregate of Google Trends data for 4 blockchain-related keywords and monthly stock returns for each blockchain firm in the sample.

Table 8. A PPMCC correlation study is conducted between the monthly aggregate of Google Trends data for 4 automotive-related keywords and monthly stock returns for each automotive firm in the sample.

Table 9: Comparison between Google Trends correlation results of both industries

\begin{tabular}{|l|rrrr|}
\hline & Blockchain & Automotive & Difference & p-value \\
\hline N & 21 & 21 & & \\
Mean & 0.189 & -0.093 & $\underline{\mathbf{0 . 2 8 2}}$ & $\underline{\mathbf{0 . 0 5 \%}}$ \\
Minimum & -0.229 & -0.455 & & \\
P50 & 0.178 & -0.156 & 0.334 & \\
Maximum & 0.663 & 0.389 & & \\
\hline
\end{tabular}

Table 9. The table summarizes the comparison between the average correlation coefficients found in the blockchain and automotive industry, as displayed in Table 7 and Table 8 . The p-value of this entire study is also found to test the significance of the results.

\section{Discussion}

CSAD, along with the other supporting analyses of stock price correlation matrix and Google Trends correlation, proves that herding behaviour is more prominent in the blockchain stock industry, as compared to the automotive stock industry, which has been taken as a representative of traditional stock industries. The CSAD results could be justified by the absence of traditional valuation metrics for blockchain stocks, the future expectations, the impact of social media, among others.

The primary reason for this significant difference in herding behaviour in the blockchain and traditional industries is due to the absence of traditional valuation benchmarks in the former. Usually, investors analyse several metrics such as the Price-to-Earnings ratio (P/E ratio), Price-to-Book ratio (P/B ratio), Return-on-Equity (ROE) among others. The absence of these traditional methods and definitive measures of stock analysis forces investors to rely on market sentiment, media hype among other non-traditional factors, rather than financial performance and rational stock pricing methods. $\mathrm{P} / \mathrm{E}$ ratio helps value a company by measuring the proportion of the current share price to its earnings per share. It is difficult to calculate the P/E ratio for blockchain firms as a number of them are currently lossmaking. Therefore, $\mathrm{P} / \mathrm{E}$, which is widely used in traditional industries to rationally value stocks, is inaccessible for investors while trading most blockchain stocks. For a similar reason, capital efficiency sheets like ROE are not available for investors in blockchain stocks. ROE essentially indicates the return on equity for shareholders, something which is difficult to compute for loss-making businesses. $\mathrm{P} / \mathrm{B}$ ratio helps investors judge whether a stock is over or undervalued by comparing the value of the firm's assets to its market capitalisation. Since blockchain firms do not have many tangible assets and most of their investment is concentrated on digital development, calculating the value of the firm's tangible assets is difficult. Therefore, the P/B ratio is largely misrepresentative for these firms. Hence, investors in blockchain stocks do not rely on $\mathrm{P} / \mathrm{B}$ ratio, which otherwise is a widely used metric for valuing stocks in traditional industries. 
Even if blockchain firms are making profits, they are expected to deliver much higher growth rates in the future, as compared to traditional stock industries, which show relatively modest growth. Therefore, investors in blockchain stocks often pay scant regard to the immediate financial performance of individual companies. This is in stark contrast to traditional industries, where investors largely base their investment decisions on the near term financial performance of the firm.

The prominent difference between the correlation matrices for stock prices of small firms in the blockchain and automotive industries can be explained by the lack of general financial knowledge in the blockchain industry. According to a May 2021 survey conducted by the Economist Intelligence Unit, 51\% respondents stated a lack of knowledge as the primary barrier that dissuades people from getting involved in the cryptocurrency and consequently, blockchain worlds (The Economist Intelligence Unit, 2021). Similarly, a 2018 Bank of Canada survey revealed that although $89 \%$ respondents had heard about Bitcoin, around 66\% had low knowledge about Bitcoin. Furthermore, this problem of financial illiteracy with regards to the cryptocurrency and blockchain worlds is prominent in those who actively engage with it as well. The survey revealed that a fifth of respondents who owned Bitcoin had low knowledge of the cryptocurrency (Bank of Canada, 2019). This lack of financial literacy regarding cryptocurrency, especially in those actively trading stocks/currency in these spheres, could be extended to the blockchain stock industry as well, and would explain why the smaller blockchain stocks move in very similar directions. The success of a few large market leaders could influence and cause price movements of many small blockchain stocks to be in tandem, as is seen in the cryptocurrency world, where the price of Bitcoin strongly influences the prices of smaller cryptocurrencies.

The correlation of blockchain stocks with Google trends, and consequently, social media, can be explained by the industry's close relationship with the cryptocurrency world, which is much more popular on social media, as compared to the automotive industry. There are various market leaders that have considerable influence over the price of cryptocurrency, and consequently, blockchain technology stocks. For example, on $13^{\text {th }}$ May, 2021, a series of Elon Musk tweets questioning the environmental impact of blockchain technology caused the blockchain stock industry to plunge (The Guardian, 2021). As evident in Graph 1, on $13^{\text {th }}$ May and the following 2 days, most blockchain stock prices fell, despite there being no change in firm-specific fundamentals. This is a clear example of herding behaviour

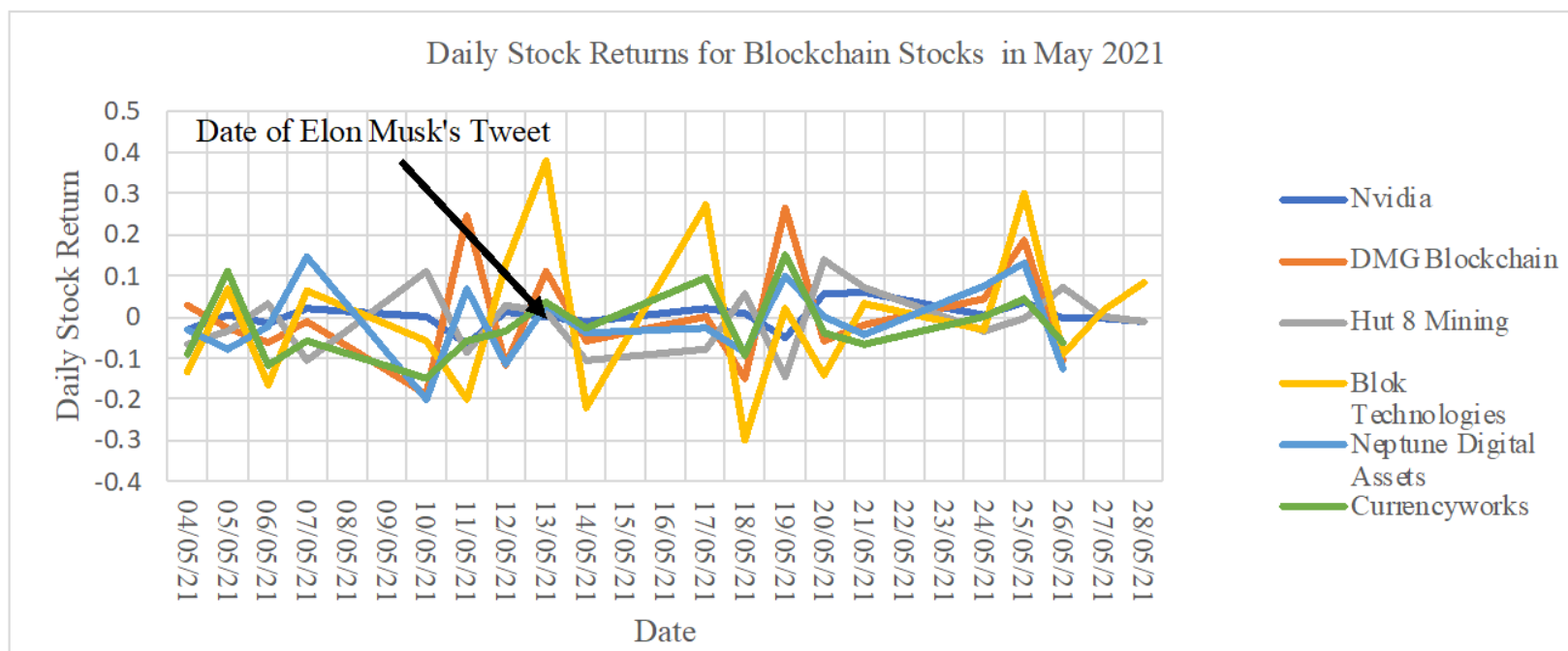

Figure 1: Daily stock returns of blockchain stocks in May 2021

Additionally, communities of social media users more actively discuss blockchain and related topics, as compared to traditional stock industry topics. For example, on Reddit, the 'Cryptocurrency' subreddit is the reddit with the $3^{\text {rd }}$ most daily comments and $10^{\text {th }}$ most daily posts in the world. This is in stark contrast to the 'Automotive' subreddit, which ranks 26,173 and 25,285 in daily comments and daily posts respectively. This data has been gathered 
from 'subredditstats.com'. Given that blockchain and its related topics are more actively discussed on social media, as compared to most traditional industries, social media user communities are likely to have a strong influence on price movements in the blockchain stock industry.

Besides this, in the Google Trends correlation study, there is a clear difference in results between the larger and smaller blockchain companies. The firms in Table 7 are listed in descending order of market capitalisation. It is evident that most of the larger stocks have negative correlation coefficients, while most smaller stocks have positive coefficients. This implies that there is likely more social media-induced herding behaviour in the smaller blockchain stocks. This finding could be explained by the fact that investors may be more well-versed with the financials of larger blockchain stock companies, as compared to smaller blockchain firms. Additionally, the data for larger firms would likely be more reliable and accessible compared to that for smaller blockchain firms. Due to these reasons, investors would be more likely to exhibit herding behaviour while trading smaller blockchain stocks.

\section{Conclusion}

This paper aims to study whether blockchain stocks exhibit more herding behaviour than traditional stock industries. Using an amalgamation of multiple data analysis techniques, the paper concludes that herding behaviour in the blockchain stock industry is far more significant than in the automotive industry. This paper can be used as a starting point for further research in this emerging industry.

\section{Limitations and Further Research}

In order to further build upon this research, fellow researchers can conduct a number of other studies that this paper was unable to cover, due to time, skill and resource constraints. To further investigate the impact of social media on herding behaviour and stock price movements, sentiment analysis around blockchain stocks on social networking applications like Twitter and Reddit can be conducted. The Stanford CoreNLP Library or IBM Watson can be used to develop the appropriate Java/Python code, in order to categorise posts under positive and negative categories. The sentiment data can be compared with stock price movements, to explore the relationship between social media-induced herding behaviour and the blockchain stock industry.

Since the paper hypothesizes that firm-specific news and financials do not play as significant a role in the blockchain industry, further research using the Capital IQ database can be conducted. Capital IQ allows researchers to gain access to a timeline of key developments for every listed stock firm. This data could be compared to the stock price movements of individual firms to see whether individual company financials indeed have a relatively insignificant impact on that blockchain firm's stock prices.

\section{Acknowledgments}

I would like to thank my advisor Abhishk Dev for helping me with this research.

\section{References}

Ballis, A., \& Drakos, K. (2020). Testing for herding in the cryptocurrency market. Finance Research Letters, 33, 101210. https://doi.org/10.1016/j.frl.2019.06.008 
Bambrough, B. (2021, April 8). Bitcoin Price Prediction: Why Bitcoin Could Rocket To \$400,000 In 2021. Forbes. https://www.forbes.com/sites/billybambrough/2021/04/08/bitcoin-price-prediction-why-bitcoincould-rocket-to-400000-in-2021/?sh=1704d61327a3

BCC Research. (n.d.). Information technology industry analysis \& market research report. https://www.bccresearch.com/market-research/information-technology

Cakan, E., \& Balagyozyan, A. (2013). Herd behaviour in the Turkish banking sector. Applied Economics Letters, 21(2), 75-79. https://doi.org/10.1080/13504851.2013.842629

Chang, E. C., Cheng, J. W., \& Khorana, A. (1999). An examination of herd behavior in equity markets: An international perspective. SSRN Electronic Journal. https://doi.org/10.2139/ssrn.181872

Christie, W. G., \& Huang, R. D. (1995). Following the pied piper: Do individual returns herd around the market? Financial Analysts Journal, 51(4), 31-37. https://doi.org/10.2469/faj.v51.n4.1918

Deloitte Insights. (2021). Deloitte's 2021 Global Blockchain Survey. Deloitte. https://www2.deloitte.com/content/dam/insights/articles/US144337 Blockchain-survey/DI Blockchain-survey.pdf

The Economist Intelligence Unit. (2021). Digimentality 2021-Digital currency from fear to inflection. https://digitalcurrency.economist.com

Gama Silva, P. (2019). Herding behavior and contagion in the cryptocurrency market. Journal of Behavioral and Experimental Finance, 22, 41-50.

The Guardian. (2021, May 13). Elon Musk says Tesla will no longer accept bitcoin due to fossil fuel use. https://www.theguardian.com/technology/2021/may/12/elon-musk-tesla-bitcoin

Gurdgiev, C., \& O'Loughlin, D. (2020). Herding and anchoring in cryptocurrency markets: Investor reaction to fear and uncertainty. SSRN Electronic Journal. https://doi.org/10.2139/ssrn.3517006

Gębka, B., \& Wohar, M. E. (2013). International herding: Does it differ across sectors? Journal of International Financial Markets, Institutions and Money, 23, 55-84. https://doi.org/10.1016/j.intfin.2012.09.003

Henry, C. S. (2019). 2018 bitcoin omnibus survey: Awareness and usage. Bank of Canada. https://www.bankofcanada.ca/2019/11/staff-discussion-paper-2019-10/

MarketWatch. (2021, July 7). Latest report on blockchain technology market size with growing CAGR of $81.2 \%$ by 2025. https://www.marketwatch.com/press-release/latest-report-on-blockchain-technology-market-sizewith-growing-cagr-of-812-by-2025-2021-07-07

NYU Stern. (2021, January). Historical growth rates. Welcome to Pages at the Stern School of Business, New York University. https://pages.stern.nyu.edu/ adamodar/New Home Page/datafile/histgr.html

SubredditStats. (n.d.). SubredditStats. https://subredditstats.com 
Vidal-Tomms, D., Ibbbez, A. M., \& Farinns Viias, J. E. (2018). Herding in the cryptocurrency market: CSSD and CSAD approaches. SSRN Electronic Journal. https://doi.org/10.2139/ssrn.3205137

Wermers, R. R. (1998). Mutual fund herding and the impact on stock prices. SSRN Electronic Journal. https://doi.org/10.2139/ssrn.136737

Zheng, D., Li, H., \& Chiang, T. C. (2017). Herding within industries: Evidence from Asian stock markets. International Review of Economics \& Finance, 51, 487-509. https://doi.org/10.1016/j.iref.2017.07.005 